\title{
REGENERATIVE DEVELOPMENT - BUILDING EVOLUTIVE CAPACITY FOR HEALTHY LIVING SYSTEMS
}

\author{
BRUNO DUARTE DIAS \\ CITAD, Lusíada University of Lisbon, Portugal.
}

\begin{abstract}
Regenerative Development is a systemic approach that sees, for example, global challenges as the climate change hypotheses, as an opportunity to develop co-agency among several cultures and fields, toward a shared purpose that can reconcile the fragmented relationship of human and natural systems and multiple problems within a place. From this point of view, human systems (business, education, food and building industries, etc.) and natural systems (watersheds, rivers, forests, ocean, etc.) are aal seen as living systems. Projects can be designed and redesigned as change agents that have the capacity to influence and develop the vitality and capacity for evolution of these living systems as a whole. Resilience and sustainability become by-products of a strong and better structured whole system. This is a review paper that aims to uncover the patterns that emerge from different fields of human endeavours were the Regenerative approach is being applied such as business, supply chains, agriculture, building industry and others. The intention is to bring concrete examples that can reveal the differences between regenerative and conventional sustainable approaches.

Keywords: Evolutionary Systems Thinking, regeneration, regenerative development, sustainability.
\end{abstract}

\section{INTRODUCTION}

Sustainability is becoming a very ambiguous term. An article revealed that until 2007 there were an estimated three hundred definitions of 'sustainability' and 'sustainable development' exist broadly within the domain of environmental management and the associated disciplines which link with it, either directly or indirectly [1].

The architect Bill Reed claims that "Sustainability is not deliverable. Sustainability is not a thing. Sustainability is not simply about efficient technologies and techniques. It is about life - a process by which living things such as forests, neighbourhoods, people, businesses, mushrooms, and polar bears ensure their viability. It is a process of reciprocal relationship - a process by which living things support and are supported by a larger whole" [2]. For example a very high energy efficient building can't be considered sustainable, because it doesn't sustain life."

Although the good intentions of sustainability goals to reduce impact and increase efficiency and effectiveness on the use of resources, these goals are a poor response considering that human population and ecological footprint are increasing at an exponential rate [3]. Most sustainable solutions aim to solve problems, but usually when we solve a problem others emerge.

For example in 2015 the increased heat and drought in California cause dams to run out of water. The solution was to fill the surface with floating black balls to stop the evaporation. Instead of going to the source of the problem, this mechanical way of solving problems generates unintended consequences. For example, in 2017, after nine years, these balls had to be removed from a reservoir in Silver Lake, LA, because its water became undrinkable [4].

\section{WHAT IS REGENERATION}

In biology, regeneration is the process of renewal, restoration, and growth that, makes genomes, cells, organisms, and ecosystems resilient to natural fluctuations or events that cause disturbance or damage [5]. The biologist Richard J. Goss argued that regeneration is a primary 
attribute of all living system, without which could be no life. To understand how nature sustains life, we need to move from biology to ecology, because sustained life is a property of an ecosystem rather than a single organism or species. Over billions of years of evolution, the Earth's ecosystems have evolved certain principles of organization to sustain the web of life [6].

\subsection{Introduction to Living Systems}

The concept explored in this paper is based in the perspective of a particular living systems thinking, school of thought. The dictionary of Etymology argue that Systems is a word that came from the Greek word "systema", that means an organized whole, a whole compounded of parts. Living system is here defined as a self-organized whole.

But as Pamela Mang argue - From a regenerative perspective “...natural systems and human systems, ... are all living systems" [7]. In the field of systems thinking, James Grier Miller defines living systems as a special subset of concrete systems. They can be composed of the moneres, protists, fungi, plants, animals, groups, organizations, societies, and supranational systems. Living systems are open systems that exchange matter-energy and information with its environment; they maintain a steady state of negentropy even trough entropic changes; they have more than a certain minimum degree of complexity; descended from some primordial DNA (deoxyribonucleic acid) common to all life, or have a charter; they are constitute of organic compounds, and in some cases, nonliving components; they have a decider system that enable the interaction of components and subsystems; they subsystems are integrated together to form actively self-regulating, developing, unitary systems with purposes and goals [8].

\subsection{Regeneration in the context of sustainability}

In the context of the field of sustainability, the term regenerative emerged for the first time connected with agriculture practice, in the paper submitted by the Rodale Institute with the title - Potential for regenerative agriculture in developing world [9]. In 1994 John Tillman Lyle introduce the term "regenerative design" as an approach to the design of urban landscapes which enables them to regenerate lost ecosystems [10].

Most approaches to sustainability focus on social and environmental health using traditional reductionist to solve problems by applying best practices. Regeneration aim to building healthy human and natural networks, drawing on universal principles and patterns, in which "sustainability" and resilience is a byproduct of systemic health [11]. Is not just about reducing impact or doing good things to nature, it is about recognizing that we are part of nature and that our activities need to be designed and integrated in a way it contribute and add to the whole, instead of just extract.

Regeneration is different form restoration, because life evolves and is not static, we can never restore a living system to its original condition. When we speak of restoration (of a woodland, a riparian system, a wetland) we are speaking of restoring a system's capability to continuously self-organize and evolve [12]. Regeneration is a concept that aims to develop will and invite people to take care of our life support system (earth systems).

\subsection{Three possible aims of regeneration}

A regenerative project or initiative always comes from an organization (company, non-governmental organization, etc.). A regenerative organization is authentic, is purposeful, it really wants to exist to make their communities (human and natural), more viable and vital. 
1. Regenerative solutions (inside the limits of propriety) - are related to concrete solutions that are applied to agriculture, agroforest, landscape, urban design, etc. When applied in context with the unique characteristics of a place, these techniques can improve the quality of the soil, retention of water, increase of biodiversity, like for example regenerative agriculture. These are great and necessary solutions, but if we design only from a solution point of view we can still design our projects as islands close to limits of the project or propriety.

2. Systemic Regeneration of place (around the project) - A project can be seen as a dynamic piece that will move the system in a way it can regenerate our degenerate several other systems to which it is connected. Before starting a design process is necessary to understand the existing web of relationships and see how the project can work with them. If well designed and implemented, a project or initiative can contribute to increasing the vitality and capacity for evolution of human and natural systems.

3. Systemic Regeneration of field of endeavour (in the world) - At this level, an organization may aim to push or regenerate how a particular field of endeavour is done in the world. For example, the Regenesis Group is an organization that is "dedicated to regenerating the way human beings develop and inhabit ecosystems".

Several projects work on just one of the above three aims. Others, like the Playa Viva example, work on all three together.

\section{REGENERATIVE DEVELOPMENT}

This concept was proposed in 1995 by the Regenesis Group a North American collaborative, composed of a multidisciplinary team. The practice process of Regenerative Development is based on the Living System School of Thought originally developed by Charles Krone, to enable thinking about organizations as living systems - what organizes and orders them, how they are structured, how they evolve, etc. It uses systemic frameworks and developmental processes to consciously improve the capacity to apply systems thinking to the evolution of human or social and natural living systems [13].

In the framework levels of work developed by Krone, Regenerate or Regeneration is a level of work that addresses the unrealized potential inherent in the relationship between a given system and the larger systems within which it is nested [2].

To "regenerate" include three key ideas: a radical change for the better; creation of a new spirit; returning energy to the source [14]. The organization working from evolutionary systems thinking sees its primary purpose as regenerating the field "they/we" all exist in and seeking to harmonize toward where the field seems to be unfolding [15].

\subsection{Main actors on the field of Regenerative Development}

According to Raymond Cole, and other main actors on the field of sustainability, Regenesis Group has provided by far the most significant contribution to defining the scope, emphasis and key principles of regenerative development [16]. The Regenesis school of thought has also inspired the development of a number of tools, such as REGEN, a regenerative design framework developed by architectural firm Berkebile Nelson Immenschuh McDowell (BNIM) for the US Green Building Council; and LENSES, a facilitation tool developed by the Institute for the Built Environment at Colorado State University [7].

This paper will consider the definitions provide by the Regenesis Group to continue exploring what Regenerative Development aim to accomplish and explore some of the thinking that 
is behind. In this paper the implications of Regenerative Design are not going to be addresses superficially, although they are an important part of the Regenesis approach.

Regenerative development is define by Regenesis as "A system of technologies and strategies for generating the patterned whole-system understanding of a place, and developing the strategic systemic thinking capacities and the self-organizing and self-evolving stakeholder engagement/commitment required to ensure regenerative design processes to achieve maximal systemic leverage and support" [17].

Sarah Jenkin and Maibritt Pedersen Zari write that regenerative development "investigates how humans can participate in ecosystems through development, to create optimum health for both human communities (physically, psychologically, socially, culturally and economically) and other living organisms and systems" [18].

\subsection{Regenerative development in practice}

It seems that Regenesis makes the translation from theory to practice of Fridjot Capra statement: "the living world evolution cannot be limited to the adaptation of organisms to their environment, because the environment itself is shaped by a network of living systems capable of adaptation and creativity. They co-evolve. The evolution of living organisms is connected with the evolution of their environment that together they constitute a single evolutionary process." The shift is from evolution to co-evolution [19].

In the book Regenerative Design and Development, the authors argue that in order to comprehend regenerative development is necessary to introduce three key ideas:

Regeneration as enabler of evolution - Regeneration enables living systems to evolve by expressing their latent potential in the form of new value in the world. In this way, what exists now can move toward what could be in the future.

Working in place - The idea of place is a way for people to envision the unity of humans and natural systems in a concrete and specific way. In each place on Earth, natural and cultural systems express themselves uniquely (although often the qualities that differentiate them are masked by the effects of media and the global economy). This means that if we wish to engage in co-evolutionary partnerships with nature, we have to do so place by place, discovering opportunities and solutions that are indigenous to specific locations rather than generic to everywhere.

Developmental processes - A regenerative development project leaves behind more than physical structures; it does more than benefit the surrounding natural and social communities. It also grows new capability and capacity in the people that it touches. This is accomplished by including human development in every aspect of a project [2].

\subsection{Regenerative development criteria}

Table 1 expresses the criteria to be considered in the work of regenerative development. This content was taken of a presentation that Ben Haggard made in the Commonwealth workshop in 2017 [20].

This table illustrates that to intervene in complex living systems it is necessary to move from a reductionist approach to a holistic one. It's important to underline that problem solving, standard and best practices are appropriated to address complicated systems (like cars or planes). But when applied to Living Systems a problem solving approach generates inefficient and ineffective solutions/designs that may generate degenerative change in the whole system.

The following definitions were draw from a document presented in the Regenerative Summit and event organized by Carol Sanford. She is a regenerative practitioner with several 
Table 1: [Seven criteria of regenerative development - Ben Haggard, presentation to RDRCC, May-18th-2017]

\begin{tabular}{ll}
\hline Moves Away From & Moves Toward \\
\hline Parts and fragments & Living wholes \\
Commonality and averages & Essence, fostering differentiation \\
Problems and ideals & Inherent, specific potential \\
Quid pro quo and transactional & Systemic reciprocity among all life \\
Isolated and independent entities & Nested Systems \\
Shotgun approaches & Nodal Interventions for systemic effects \\
Command and control & Development of capacities \& capabilities \\
\hline
\end{tabular}

decades of experience, using exactly the same Living Systems School of Thought, but applied to the field of economy, business, entrepreneurship, etc.

Carol Sanford argues that, Regeneration is found only in the world of living systems. It offers us a paradigm for understanding life. Machine and other non-living metaphors cause us to conceive inaccurately. Living Systems offer us a set of First criteria that allow us to understand the world as alive and "at work". A regenerative approach can be accessed through these seven foundational Criteria [21].

First criteria

Whole - systems, businesses, industries are living wholes. We tend to work on the parts as problems with considering the effects on the whole that we want to regenerate.

Essence - By honour and work from the singular characteristics of a being (person, company or place) we are able to discern the conditions in which a being is likely to thrive.

Potential - instead of looking to solve problems by applying best practices or imported ideas, projects are designed from the potential, or what could be but is not yet manifested.

Reciprocity - reciprocity aim to establish relationships of mutual benefit that benefit the system health with care for contributions and outcomes for all.

Nested Systems - Embedded within greater and lesser systems, each playing a core role in the success of the whole and other nested wholes.

Nodal - Seeking points for intervention that evoke systemic beneficial effects that have significance to the system. Similar to acupuncture, where a single point or set of points are recognized as most effective for systemic regeneration.

Development - Instead of trying to control, regeneration seeks to grow and develop capacity and capability in each and all entities to realize their essence.

Regeneration is not about technology or solutions. Regeneration is a way of thinking and a way of being in the world. Solutions are part of the equation but they only start to become concrete in a late phase of the design process.

\section{TWO EXAMPLES OF APPLY REGENERATIVE DEVELOPMENT FRAMEWORKS}

\subsection{Regenerative development to reverse climate change}

The Commonwealth and the Cloudburst Foundation organized the Workshop "Regenerative Development to Reverse Climate Change" in London from 28 to 29 November 2016 to 
launch a process to develop a viable, comprehensive and effective program for regenerative development. From around the world, a group of over 50 leading experts from multiple fields came together to share and discuss ideas on policy, technology and best practice. This notion of cooperation or collaboration fosters another way of seeing sustainability, which is grounded in the mind-set to reduce or mitigate the impacts we generate.

Hopefully, Regenerative Development has the potential to realize and exceed the Paris Agreement on climate change, and the Sustainable Development Goals to end poverty and hunger, boost economic growth, reduce inequality and maintain peace and stability. It is a re-thinking of the way we live with our land, forests, cities and oceans. It is based on the idea that we can rebuild ecological health, socio-cultural vitality, economic value and human potential in an integrated and reciprocal way [22].

As Ben Haggard argue "The technologies and strategies we are talking about need to be undertaken in consultation with local people. This is key to the idea of regeneration. What we are really up to here is building new capacity into every community, nation and ecosystem where these strategies are applied. So it is not just the strategies, it's also the capacity that is being built into the systems surrounding those strategies. This is how reversing climate change also becomes an engine for social and economic regeneration" [22].

\section{Case study conclusion}

Regenerative development is an integrative and inclusive concept by nature. It has the ability to look at the uniqueness of a situation or project and merge other tools and concepts, not because is on a check list, but because they are appropriated and can add value in a particular context.

\subsection{Example - Playa Viva eco-resort}

This eco-resort was implemented in a 86 hectares plot located in Zihiuatanejo, Baja California, Mexico. The master plan includes 60 Casitas, 13 single lots, a town square and a boutique hotel.

Initially, with a sustainable mind set, the main goals were to produce all the energy on site from renewable sources, use eco-friendly building materials and local building techniques.

After engaged in a systemic regenerative thinking approach the master plan of the resort took a different direction [2].

Regenesis developed a tree part process that is flexible and adaptable to the particularities of each project. This case study will be framed in this three part process although in reality the process is much more complex and organic.

\section{Research Phase - Understand place}

Before the design process begin is important to "understand the site and its community in relationship to place, through the dynamics, patterns, relationships and potential inherent in that specific place; and to conceptualize how, through right relationship, the project can be a regenerative force" [7].

Some of the things that emerged were: that property and the adjacent land were ecologically degraded after 80 years of intensive palm oil farming. The young population was leaving this rural area for lack of work. The resort beach was a turtle nesting area. Local people dug up, sold and consumed turtle eggs (illegally) which lead to the decline of the turtle popula- 
tion. One of the slopes on the property was the remaining structure of a pre-Columbian pyramid. That area had been a trading centre of the Aztec empire.

After having a notion of the particularities of the whole system, gradually began to realize how could integrate the project of the resort in this natural and human system [23].

\section{Design phase - Designing for harmony}

The aim is to harmonize the buildings or infrastructure with the patterns of the land and its cultural and ecological systems, to improve all, including the inhabitants of the place [24].

The design team and the developer try to understand what could be the role of the project in this place, that lead to the development of the master plan and several programs and initiatives:

The "Viva Praia Reserve" - a program was started with the aim of regenerating 73 hectares of the property, the coastal forest and the mangrove. They built a nursery of native and ornamental plants, controlled invasive species such as acacia, cleaning and restoration of rivers and streams, and improved water quality so that shrimp and other native bird species returned to the area [13].

Living beach Turtle Sanctuary - After understanding the importance of turtles to the ecological system, a program was created that was of local interest. It was made a maternity of turtles, the turtle hunters were hired by the resort to unearth and incubate the turtles. These program is an intersection of tourism and conservation, the aim is to increase the turtle population and also transformed the hunters in protectors [25].

Relationship with the community - Instead of the resort being thought to be an entertainment island, closed to the local community, the resort become the support for local development promoting social, natural and economic vitality. At one point local authorities offered the developer the possibility of make a direct access from the motorway that passed outside the local village. An offer that the developer refused because he realized that the community and the visitors could benefit each other from their passage inside the village [7].

\section{Operational phase - Co-evolution}

A regenerative project aims to set conditions in place which will ensure ongoing co-evolution and mutually beneficial integration of human and natural systems [25].

Playa viva resort opened in November 2009 using a living systems framework of adaptive, co-evolutionary growth. It made considerable changes at the economic environmental and social development of the community. The aim was to continue to develop the community in sustainability education, like permaculture design and recycle workshops. A Co-op of salt emerged from the interaction of the resort and local producers, to ensure quality and fair trade. The resort started some actions with the local community. Together with the local schools they set up cleaning days to keep the village, forest and rivers cleaner, and explained the benefits of waste separation. Do agriculture actions and plant trees outside and inside the resort. They supported and provided school and medical supplies to the population, the resort offered organic farming programs to locals, who subsequently began to provide organic food to the hotel and local markets [7].

Transformative experience for visitors - In addition to the experience of releasing turtles, tourists have the possibility of contacting stakeholders who regenerate natural systems, participate in local ecological projects, and participate in initiatives within schools.

Regenerative resorts - this is the latest project lead by David Leventhal (Playa viva owner). This project aims to build a collaborative of resorts that can expand the impact 
investment community. This illustrates the Systemic Regeneration of the field of endeavour, this project aim to make significant changes on what can be the role of a resort in a particular place [26].

\section{Case study conclusion}

There is a long list of projects and programs that are being develop by the Resort. What is present here is the culture of, what can we do more? How can we evolve the capacity of the systems that we are interdependent with?

Even the concept of success was redefined. Bill Reed one of the element of the project team stated that "the greatest success of this project can be seen by the return of young people to their village, increased biodiversity, economic and social vitality of the village, changing farming practices, egg hunters who became guardians of the turtles, etc." In another words the success is measured outside the limits of the project.

Instead of this project being thought to extract value from visitors and local communities the focus is to generate value in local human and natural systems, knowing that this will contribute to the viability of the Resort in such a way that it has become vital and nondispensable for the area.

Playa viva is a purposeful business that acts as a change agent were social responsibility and innovation are weave together and connected with the well-being of social and natural communities.

\section{CONCLUSION}

Only a few decades ago "civilized man" started to understand the complexity of the world and the impact that human activities have on the systems that support life. Until now we develop a extractive and passive mind-set, we take what we can without giving back. To make real changes our role must shift to become active in developing relationships of mutual reciprocal benefits between human and natural communities.

The practice of Regenerative development aims to take people and their endeavours from their assigned boxes, to open the possibilities of what a project or business can do for all the stakeholders involved.

Regenerative development is a change process that aims to reconcile and harmonize how human/social systems work with natural systems. It's a systemic approach that aims to build in projects, business and communities the capacity to regenerate the whole system. Any project or business can be the entry point to address the health of the whole system, if people can leave there assign and unassigned list boxes and open to the possibilities of the role that each person and organization can bring to place that inhabit.

\section{ACKNOWLEDGEMENTS}

This work was made at CITAD - Research Centre for Territory Architecture and Design funded by National Funds through FCT - Foundation for Science and Technology under the Project UID/AUR/04026/2013

\section{REFERENCES}

[1] Johnston, P., Everard, M., Santillo, D. \& Robèrt, K.-H., Reclaiming the definition of sustainability. Environmental Science and Pollution Research - International, 14(1), pp. 60-66, 2007. https://doi.org/10.1065/espr2007.01.375

[2] Mang, P. \& Haggard, B., Regenerative Development and Design - A Framework for Evolving Sustainability, Wiley \& Sons: Hoboken, New Jersey, 2016. 
[3] Dias, B.D, Beyond Sustainability - Biophilic and Regenerative Design in Architecture, European Scientific Journal, 2015.

[4] CURBED, Ivanhoe Reservoir' s shade balls are going away very soon, available at https://la.curbed.com/2017/4/4/15182772/ivanhoe-reservoirs-shade-balls-removed (Accessed 10 March 2018).

[5] Birbrair, A., Zhang, T., Wang, Z-M., Messi, M.L., Enikolopov,G.N., Mintz, K. \& Delbono, O., Role of pericytes in skeletal muscle regeneration and fat accumulation. Journal of Neurotrauma, 4126, pp. 1-65, 2015.

[6] Capra, F., Ecoliteracy in your Inbox!, available at https://www.ecoliteracy.org/article/ new-facts-life (accessed 03 March 2018).

[7] Hes, D. \& Du Plessis, C., Designing for Hope. Routledge: Abingdon, 2014.

[8] Miller, J.G., James Grier Miller Living Systems . Panarchy.Org, pp. 1-37, 1978.

[9] Terra Genesis International, "Levels of Regenerative Agriculture," September, 2016.

[10] Doyon, A. \& Hes, D., Positive buildings, an opportunity to increase resilience, 2014.

[11] Fullerton, J., How Universal Principles And Patterns, 2015.

[12] 7group and Reed, B., The Integrative Design Guide to Green Building - Redefining the Practice of Sustainability, John Wiley \& Sons: Hoboken, 2009.

[13] Mang, P. \& Reed, B., Designing from place: a regenerative framework and methodology. Building Research \& Information, 40(1), pp. 23-38, 2012.

https://doi.org/10.1080/09613218.2012.621341

[14] Mang, P. \& Regenesis Group, "Regenerative design and the evolution of the sustainable design field," 2001.

[15] Sanford, C., A theory and practice system of 'systems thinking ': with an executive ' s story of the power of ' developmental' and ' evolutionary' systems thinking. Why a New Typology of Systems Thinking ?, pp. 1-23, 2004.

[16] Cole, T.R.J. \& Oliver, A., The Next Regeneration, 2012.

[17] Mang, P. \& Reed, B., Regenerative development and design. Encyclopedia of Sustainability Science and Technology, I, pp. 8855-8879, 2012. https://doi.org/10.1007/978-1-4419-0851-3_303

[18] Zarim, M.P. \& Jenkin, S., "Degenerative Development," no. 1, pp. 1-10, 2009.

[19] Capra, F., The Web of Life: A New Scientific Understanding of Living Systems. New York: Anchor Books, 1996.

[20] The Commonwealth, "The Commonwealth and Cloudburst' s Workshop on Regenerative Development to Reverse Climate Change Table of Contents," 2016.

[21] Sanford, C., What Is Regeneration?, 2017 available at https://theregenerativebusinesssummit.com/regeneration/ (accessed 20 February 2018).

[22] The Commonwealth, "Regenerative Development to Reverse Climate Change Workshop," 2017.

[23] Group, R., "Playa Viva - More Than a Sustainable Development." available at http:// regenerationalliance.com/projects/playa-viva/ (accessed 30 March 2018).

[24] Stay, B.Y., Contest, P., Resort, E., Hotel, E., Tourism, S., Eco, F., Lodge, L., Retreat, E., Kahn, S. \& Leventhal, D., History : The Playa Viva Story History of Place : Archaeological Site, 2017, available at http://www.playaviva.com/en-gb

[25] Luna, M., Taking a hard look at recent developments. Director, available at https://playaviva.wordpress.com/2017/08/28/taking-a-hard-look-at-sustainable-seafood/ (accessed 05 March 2018).

[26] Leventhal, D., "VALUES WHO WE ARE," 2018, available at www.regenerativeresorts. com (accessed 30 March 2018). 